\title{
Evaluation of the effectiveness of the use of humic substances as washing agents of oil-contaminated soils
}

Grechischeva N.Yu. ${ }^{1}$, Fakhretdinova D.R. ${ }^{1}$, Murygina V.P. ${ }^{2}$, Gaydamaka S.N. ${ }^{2}$

${ }^{1}$ National University of oil and gas "Gubkin University", Moscow, Russia, yanat2@mail.ru

${ }^{2}$ Lomonosov Moscow State University, Moscow, Russia

Keywords: oil-contaminated soil, surfactants, humic substances, wash-out agents

doi: 10.36291/HIT.2019.grechischeva.114

A huge amount of oil polluted soils are located in Russia. The solvent/chemical surfactant washing technique is widely applied for the oil-contaminated soils, but use of it leads to soil recontamination. Natural surfactants based on humic substances (HS), the active matrix of organic matter of soils, peats, natural waters, can be an alternative to chemical surfactants.

The aim of this research is evaluation of the prospects for the use of humic substances as washing agents compare to chemical surfactants in the remediation of oilcontaminated soils.

Gravimetric analysis determination of oil content showed that coal HS "Powhumus" is the most active washing agent towards both the native oil-contaminated soil and to model systems. The use of Powhumus reduced the content of oil hydrocarbons from 5.00 to $1.81 \%$ in the case of model systems and from $28.96 \%$ to $12.79 \%$ for native oilcontaminated soil. The action of Powhumus is comparable to the well-known synthetic surfactant (sodium lauryl sulfate). It is shown that the effectiveness of the Powhumus increases by $20 \%$ upon condition of oil-degradation preparation "Rhoder" use. The introduction of oil degradation microorganisms contributes to the formation of more favorable conditions for the development of soil microorganisms and the degradation of soil contamination. The analysis of group composition of residual oil contamination of soil washed various surfactants and subsequent application of the biological product showed that Powhumus is the most effective agent for the removal of light and heavy oil hydrocarbons of contaminated soils. The coal humic substances "Sakhalin" are more effective for removal of oil polyaromatic hydrocarbons from contaminated soil. In use of water and synthetic surfactants as washing agents of oil-contaminated soil, the natural microbiota of the contaminated soil was suppressed. In use of the natural surfactants based on humic substances led to the development of Pseudomonadaceae, Rhodococcus, Bacillaceae, Sarcina soil bacterial community. 